\title{
How Far Does Economic Theory Explain Competitive Nonlinear Pricing in Practice?
}

\author{
by
}

\author{
Stephen Davies \\ ESRC Centre for Competition Policy, University of East Anglia \\ $\&$ \\ Catherine Waddams Price \\ ESRC Centre for Competition Policy, University of East Anglia \\ \& \\ Chris M. Wilson \\ School of Economics, Loughborough University
}

\section{CCP Working Paper 09-7}

\begin{abstract}
Liberalisation of the British electricity market, in which previously monopolised regional markets were exposed to large-scale entry, is used to test the propositions of several recent theoretical papers on oligopolistic nonlinear pricing. Consistent with those theories, each oligopolist offered a single two-part electricity tariff, and a lump sum discount to consumers who purchased both electricity and gas. However, inconsistent with those theories, firms' two-part tariffs are heterogeneous in ways that cannot be attributed to cost. We establish a series of stylised facts about the nature of these asymmetries between firms and use them to confront established theory.
\end{abstract}

May 2009

JEL Classification Codes: D43, L43, L94

Keywords: oligopolistic nonlinear pricing, two-part tariffs, asymmetric equilibria, retail electricity, collusion 


\section{Acknowledgements:}

The support of the Economic and Social Research Council (ESRC) is gratefully acknowledged. We thank Khac Pham and Hieu Tran for their excellent research assistance. We appreciate helpful comments from Mark Armstrong, Severin Borenstein, Paul Dobson, Morten Hviid, Stephen Littlechild, John Vickers, Mike Waterson and participants at seminars at the Electricity Policy Research Group at Cambridge, the International Industrial Organization Conference at Atlanta, Georgia, the Competition Law and Economics European Network workshop in Bonn, Norges Handelshøyskole, Bergen, and the Centre for Competition Policy, Norwich.

\section{Contact details:}

Stephen Davies, ESRC Centre for Competition Policy, University of East Anglia, Norwich, NR4 7TJ, UK

s.w.davies@uea.ac.uk 


\section{Introduction}

Nonlinear pricing is frequently observed in real world oligopolistic markets, often in the form of scale discounts which are not totally explicable in terms of costs. Yet the theory of oligopolistic nonlinear pricing (or second degree price discrimination more generally) remains incomplete and largely untested. In a significant development, two papers (Armstrong and Vickers 2001 and Rochet and Stole 2002) have offered the striking suggestion that firms should offer single cost-based ${ }^{1}$ two-part tariffs in any symmetric equilibrium. Furthermore, when consumers are able to buy two goods either from one firm or two, Armstrong and Vickers (2008) extend this intuition to suggest that firms may also employ a lump sum discount as a form of mixed bundling. This paper uses the liberalisation of the British retail electricity (and gas) industries to examine how these predictions compare to the development of oligopolistic tariff competition in practice.

Consistent with these theories, we find that each firm did offer a single two-part electricity tariff and that the discounts offered to consumers who chose to purchase both electricity and gas were indeed lump sum. However, inconsistent with the theoretical literature, we show that firms' tariffs are heterogeneous in ways that cannot be attributed to cost and that, rather than decreasing, these tariff asymmetries have increased over time. We establish a series of stylised facts to explore this finding further. Among other results, we find that i) relative to the incumbent, individual entrants typically set higher fixed fees and lower marginal prices, and ii) despite symmetric costs, individual entrants showed differences in their tariffs that were systematic across regional markets and time, with some entrants regularly favouring fixed fees (marginal prices) that were much higher (lower) than the incumbents', while others typically remained much closer to the incumbent.

The existing empirical literature on nonlinear pricing has expanded considerably in recent years. ${ }^{2}$ However, our approach and results differ from these papers in three

\footnotetext{
${ }^{1}$ We use cost-based to refer to a tariff where marginal price equals marginal cost.

${ }^{2}$ As discussed below, much of the literature is based on the US Cellular telephone market (Busse 2000; Miravete and Röller 2004; Miravete 2007; Seim and Viard 2008). Others consider the market for Yellow Pages (Busse and Rysman 2005) or speciality Coffee Shops (McManus 2007). Leslie (2004) estimates the welfare effects of price
} 
respects. First, we examine tariffs at the level of individual firms, highlighting the importance of tariff asymmetries, rather than considering regularities across firms. ${ }^{3}$ We introduce a simple summary statistic for a two-part tariff, the ratio of the fixed fee to marginal price, which we term a tariff 'weighting', and show that firms' tariff weightings differ significantly and systematically. Second, unlike much recent empirical research which employs fully specified structural models (e.g. Miravete and Röller 2004 and McManus 2007), we focus on establishing a series of stylised facts through descriptive and reduced form analysis. This provides more freedom to explore the empirical data and enables us to offer an informative complement to the existing literature, especially in a context where theoretical understanding remains under-developed, though it limits our ability to compare counterfactuals. Third, consistent with the theories of Armstrong and Vickers (2001) and Rochet and Stole (2002), we identify a market where each oligopolist employs a single two-part tariff, rather than the multiple tariff options commonly documented elsewhere in the literature (Busse 2000, Miravete and Röller 2004 and Seim and Viard 2008). ${ }^{4}$

The next section briefly introduces the market. Section 3 summarises the recent theoretical literature and extracts some key propositions, which are then tested in section 4. Section 5 explores the nature of the heterogeneity amongst firms' tariffs. Section 6 discusses some implications of our findings, identifies potential future research and concludes.

\footnotetext{
discrimination at a Broadway theatre. Cohen (2008) provides evidence of price discrimination through the package size of paper towels, while controlling for cost factors.

${ }_{3}^{3}$ For example, Miravete and Röller (2004), Busse and Rysman (2005) and Seim and Viard (2008) all document how competition reduces the level of prices on average across firms and how the reduction is greater for tariffs aimed at consumers with higher usage.

${ }^{4}$ McManus (2007) also examines the empirical implications of Armstrong and Vickers (2001) and Rochet and Stole (2002), in the context of product size in the speciality coffee market. Consistent with the two theories' predictions, he finds that product sizes are close to the efficient level in the most competitive product category. However, more in line with the monopoly prediction, he also finds that product sizes are inefficiently small for other types of coffee.
} 


\section{The Market}

The retail sector of the electricity industry in Great Britain ${ }^{5}$ was traditionally separated into 14 geographical regions, each with an incumbent monopolist; consumers were only able to buy from their local incumbent, and arbitrage was not possible. The industry was privatised in 1990/1, and the household retail sector was opened to competition in 1998/9. Thereafter, significant entry occurred and consumers were free to switch away from their regional incumbent (or any subsequent supplier) to any entrant within their region without financial penalty. The average prices of incumbents (although not entrants') continued to be regulated until April 2002 but no regulatory constraint was imposed on tariff structures (Harker and Waddams Price 2007). Suppliers' freedom to offer alternative tariff structures was confirmed in the privatisation act which explicitly permits but does not mandate twopart tariffs (Electricity Act 1989 section 18(3)).

The product is essentially homogenous but households vary significantly in their levels of consumption. In all regions, the volume distribution of household consumption is positively skewed and approximately lognormal. Figure 1 shows the aggregate national distribution. It is conventional in official statistics (e.g. Ofgem 2003, p.49) to report data for low, medium and high consumption levels, defined respectively as 1,650, 3,300 and 4,950 $\mathrm{KWh} /$ year. These levels will be employed later in the paper, and Figure 1 confirms that they approximately correspond to the divisions between the four quartiles: 2,016, 3,479 and 5,567. The mean and variance of household consumption are broadly similar across the regions.

Firms are obliged to offer three alternative payment methods between which consumers are free to choose - standard credit, direct debit and prepayment. ${ }^{6}$ Nearly all electricity suppliers are also active in the gas market, which was liberalised a few months earlier. They have increasingly participated in mixed bundling by

\footnotetext{
${ }^{5}$ Electricity supply comprises four vertical stages (generation, transmission, distribution and retail); here, we are concerned only with the retail sector, in which the main functions are purchasing the upstream functions, sales, marketing and billing to final consumers.

${ }^{6}$ These are effectively three separate markets, catering for consumers who seek different billing arrangements, rather than a single market with multiple tariff options.
} 
offering a 'dual-supply discount' to consumers who buy both fuels from the same supplier.

Following liberalisation, there was almost $100 \%$ cross-entry by the original regional incumbents into each others' markets. The incumbent gas supplier also entered all regions, as did a few small Independents; see Table 1. Later, there was a gradual exit of Independents, but the main feature was the steady consolidation amongst incumbents. $^{7}$ This began around the time of liberalisation, with the acquisition of four of the smaller incumbents, and continued over the following four years with the purchase of five other incumbents. By autumn 2002 the surviving electricity retailers had consolidated into 5 major companies, and at the beginning of 2006, these five survivors (each now owning ex-incumbents in two or three regions) and the previous gas incumbent, British Gas, were the only suppliers. ${ }^{8}$

Figure 1: National Cumulative Distribution of Household Electricity Consumption

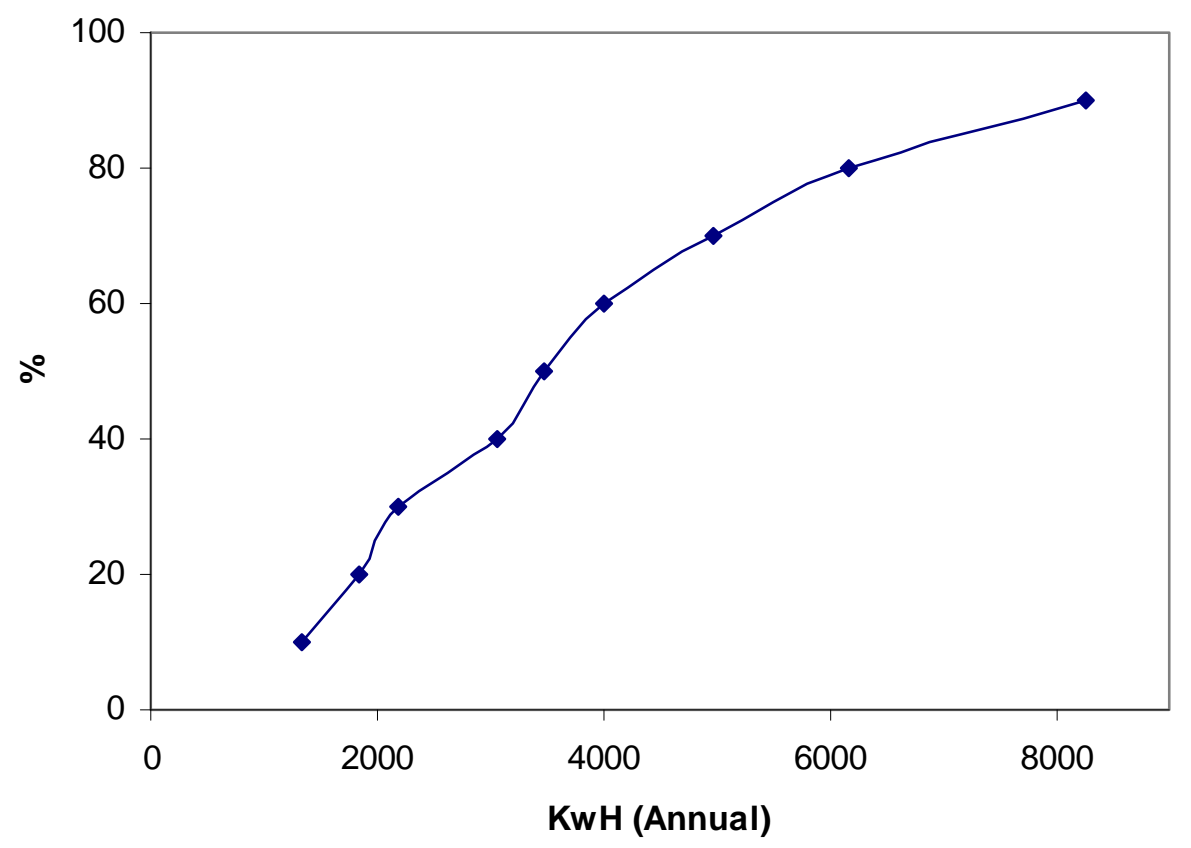

Figure 1 is constructed from data for residential consumers, using standard credit single fuel tariffs, reported in The Expenditure and Food Survey - a stratified representative national sample - for April 2002 - April 2003.

\footnotetext{
${ }^{7}$ The figures in Table 1 are net and conceal turbulence in independent entry/exit.

${ }^{8}$ Other small independent companies have entered since, but most have not survived
} 
Table 1: Firm Numbers

\begin{tabular}{|l|c|c|c|c|c|}
\hline & Majors & $\begin{array}{c}\text { Minimajors } \\
\text { (Small majors) }\end{array}$ & Independent & $\begin{array}{c}\text { British } \\
\text { Gas }\end{array}$ & Total \\
\hline Feb 99 & 5 & 7 & 1 & 1 & 14 \\
\hline Oct 99 & 5 & 7 & 2 & 1 & 15 \\
\hline Jun 00 & 5 & 5 & 3 & 1 & 14 \\
\hline Dec 00 & 5 & 5 & 3 & 1 & 14 \\
\hline Jun 01 & 5 & 5 & 3 & 1 & 14 \\
\hline Dec 01 & 5 & 2 & 3 & 1 & 11 \\
\hline Jun 02 & 5 & 2 & 3 & 1 & 11 \\
\hline Dec 02 & 5 & 2 & 3 & 1 & 11 \\
\hline Jun 03 & 5 & & 2 & 1 & 8 \\
\hline Dec 03 & 5 & & 2 & 1 & 8 \\
\hline Jun 04 & 5 & & 1 & 1 & 8 \\
\hline Dec 04 & 5 & & 1 & 1 & 7 \\
\hline Jun 05 & 5 & & 1 & 1 & 7 \\
\hline Dec 05 & 5 & & & 1 & 6 \\
\hline thereafter & 5 & & 2 & 1 & 1 \\
\hline
\end{tabular}

Typically, most firms operated in all 14 regional markets. The exceptions are the two Scottish regions, in which there were fewer firms in the earlier periods.

Hereafter, we refer to five 'types' of firm competing in any regional market as follows.

- Incumbents within their home region, who should enjoy a first-mover advantage and potential consumer loyalty.

- British Gas. Although an entrant, this was the previous nationwide incumbent gas supplier and therefore has a familiar brand name.

- Established firms outside their home regions. When selling to consumers outside their home regions, incumbents from other regions might be viewed by consumers as entirely new entities, unable to transfer brand loyalty across regions. Within this group we distinguish:

o Majorsaway - the five surviving original electricity incumbents. These are all vertically integrated and four are now subsidiaries of some of Europe's largest multinational energy companies;

o Minimajorsaway - the other original incumbents who were subsequently acquired by the Majorsaway.

- Independents. These firms have no region of previous incumbency. 
While disaggregated data on market share by firm and region over time are unavailable, we do know that in the eight years after liberalisation, nearly half of all consumers moved away from their regional incumbent, and all incumbents gradually lost market share. Typically, by 2005 , their market share was just over $50 \%$ in their home region, with British Gas accounting for about 22\%, and the Majorsaway for about 26\% (Ofgem 2008). ${ }^{9}$ The share of Independents rarely exceeded $1 \%$ in any region at any time.

\section{Theoretical Literature}

The standard results of nonlinear pricing under monopoly are well known (e.g. Mussa and Rosen 1978 and Maskin and Riley 1984). Consumers are assumed to possess private information about their tastes in the form of a single parameter drawn from a known and well behaved distribution where, in line with the single crossing property, higher types are assumed to exhibit a higher marginal utility over all units. If, in addition, consumers have a type-independent outside option, the monopolist's optimal price-quantity schedule is concave such that larger buyers are offered a lower average price per unit. Equivalently, the monopolist should offer a menu of two-part tariffs, each with a different marginal price, $p$, and fixed fee, $F$. In order to extract larger rents from higher types and prevent them from selecting a tariff intended for a lower type, marginal prices are inflated above marginal cost for all but the highest type.

The literature on oligopolistic nonlinear pricing is less well established and remains highly dependent upon modelling assumptions (see the reviews by Stole 2007 and Armstrong 2006). We will focus on two branches of this literature, both relevant to a market where firms supply two products, such as electricity and gas. The first assumes 'one-stop shopping' such that consumers can buy, at most, from a single supplier. The second allows consumers to partake in 'multi-stop shopping', in that they may buy different products from different suppliers, but cannot purchase the

\footnotetext{
${ }^{9}$ Since then, the incumbent average market share has fallen further with the Majorsaway increasing their share to about $30 \%$.
} 
same product from more than one firm. While the latter branch appears more consistent with the British electricity and gas markets where consumers may choose a different supplier for each good, the first branch is instructive in offering a simpler perspective of the basic propositions. ${ }^{10}$

In the one-stop setting, the related propositions of Armstrong and Vickers (2001) and Rochet and Stole (2002) are of particular interest and we refer to them as AV and RS hereafter. ${ }^{11}$ A simplified version of the two models is now presented in the case where firms sell only a single good, such as electricity, but AV extend the results to a multi-product setting. Two firms, $j=L, R$, are located at either end of a unit line and have symmetric per-consumer costs, $C(q)$. AV assume the firms have a marginal cost, $c$, and a fixed cost of serving one consumer, $k$, whilst RS assume the firms have a strictly convex cost function. In a one-shot game, each firm simultaneously sets a price-quantity schedule, $T_{j}(q)$, to a unit mass of fully rational consumers. The consumers exhibit two forms of unobserved, independent heterogeneity. First, as in the monopoly case, consumers are heterogeneous in their marginal utility over all units of consumption, $\theta$. This is labelled vertical heterogeneity. Second, consumers also exhibit horizontal heterogeneity. Specifically, they incur transport costs that are independent of consumption volume, as captured by the consumer's location, $x \in[0,1]$, and a travel cost parameter, $\sigma$. Assuming that the two forms of heterogeneity enter the utility function additively and separately, a consumer located at point $x$ receives a utility of $U(\theta, q)-\sigma x-T_{L}(q)\left(\right.$ or $\left.U(\theta, q)-\sigma(1-x)-T_{R}(q)\right)$ if he purchases $q>0$ units from firm $L$ (or $R$ ). Each consumer's taste parameters, $\{x, \theta\}$, are drawn from independent distributions. ${ }^{12}$ Proposition 1 follows under the further assumption that the market is covered in equilibrium such that all consumers

\footnotetext{
10 A third branch (e.g. Miravete and Röller 2004), assumes consumers may buy the same product from different suppliers, but this assumption is inappropriate for the present market,

${ }^{11}$ RS present their model in the context of quality, rather than quantity, discrimination, but as the two forms are often interchangeable, we refer to their results in the context of quantity discrimination.

${ }^{12} \mathrm{AV}$ allow $\theta$ to be multi-dimensional and place no restrictions on its distribution or the form of the utility function but present their results with the assumption that $x$ is distributed uniformly. RS assume $\theta$ is drawn from $H(\theta)$ with a utility function such that the single crossing property holds, and that $x$ is drawn from $G(x)$ which is symmetric and log concave.
} 
buy. ${ }^{13}$ A similar result can also be found for the case of an $n$-firm oligopoly (see RS, Proposition 7).

Proposition 1 (one-stop shopping, single product): Under the assumption that i) the market is covered in equilibrium for all types; ii) costs are symmetric; and horizontal preferences are iii) independent of vertical preferences and iv) symmetrically distributed, the unique symmetric equilibrium involves all firms offering a single, identical two-part tariff, $T(q)=F+p q$, where the marginal price is equal to marginal cost, $p=C^{\prime}(q)$.

Thus, in contrast to the wide variety of largely non-cost-related tariffs offered by an optimising monopolist, Proposition 1 suggests that the introduction of competition may prompt firms to adopt a single, identical two-part cost-based tariff. The existence of this equilibrium largely derives from the fact that the equilibrium would remain unchanged even if the vertical preference parameter, $q$, of each consumer was common knowledge. With such information, it can be shown that a firm would best respond to its rival's choice of a cost-based two-part tariff, by offering each consumer its efficient quantity for a total price of $F+C^{\prime}(q) q$. However, such a strategy can still be implemented without knowledge of vertical preferences, by using the proposed cost-based two-part tariff. For uniqueness, we also know that in any other symmetric outcome, a supplier could increase its profits by offering a costbased two-part tariff, as by doing so it could generate a higher consumer surplus via the efficiency properties of pricing at marginal cost.

The second branch of the literature allows for multi-stop shopping and has received less attention. We focus on the two-good scenario in Armstrong and Vickers (2008), corresponding to the case of electricity and gas. The model assumes that two firms, $j=L, R$, each sell two goods $i=1,2$, with symmetric marginal costs, $c_{i}$. As before, consumers exhibit independent horizontal and vertical heterogeneity. However, horizontal heterogeneity is now expanded to include an independent location parameter for each good, $\left\{x_{1}, x_{2}\right\}$. Just as we observe in the electricity market,

${ }^{13}$ Specifically this is from i) AV Proposition 5 for the case of a single good, where uniqueness is further later demonstrated in Armstrong and Vickers (2006, Proposition 1) and ii) RS Proposition 6 under an assumption of a symmetric distribution. 
consumers can choose to purchase both goods from the same firm or buy one good from each supplier for an extra shopping cost of $z \geq 0$. Firm $j$ 's tariff choices can be disaggregated into a tariff for consumers who buy just good $1, T_{1}^{j}\left(q_{1}\right)$, a tariff for consumers who buy just good $2, T_{2}^{j}\left(q_{2}\right)$, and a two-product tariff for consumers who buy both goods, $T_{12}^{j}\left(q_{1}, q_{2}\right)$. Assuming that all consumers buy both goods in equilibrium, Proposition 2 extends the logic of the one-stop shopping case in Proposition 1 (Armstrong and Vickers 2008, Proposition 3):

Proposition 2 (multi-stop shopping, two products): Under the assumption that i) the market is covered in equilibrium for all types and both goods; ii) costs are symmetric; and horizontal preferences are iii) independent of vertical preferences and iv) symmetrically distributed, a symmetric equilibrium exists where each firm sets three cost-based two-part tariffs, where the two-product tariff is composed of the sum of the single product tariffs minus a lump sum discount, $\delta>0$, such that $T_{i}\left(q_{i}\right)=F_{i}+c_{i} q_{i}$ for $i=1,2$ and $T_{12}\left(q_{1}, q_{2}\right)=\left(F_{1}+F_{2}-\delta\right)+c_{1} q_{1}+c_{2} q_{2}$.

Thus, under assumptions (i)-(iv), both branches of the literature predict that electricity suppliers would use identical cost-based two-part tariffs. But how applicable are these assumptions to the UK electricity and gas markets, and, if not, does theory offer any alternative predictions? A priori, assumptions (i) and (iii) seem reasonable in this context, but (ii) and (iv) are more debatable.

\section{(i) market coverage}

As electricity and gas are minimally differentiated essential goods, the market is likely to be covered; indeed, Armstrong and Vickers (2008) cite the UK market as a motivating example for their model. ${ }^{14}$

(iii) independent heterogeneity

There is no obvious reason to expect vertical and horizontal preferences to be correlated. ${ }^{15}$

\footnotetext{
${ }^{14}$ Although not all households are connected to the gas network, because of the expense of extending it to rural areas, nearly all of those which are consume gas.

${ }^{15}$ If the market is not covered, or if horizontal and vertical preferences are correlated, the literature predicts that firms are more likely to select a symmetric menu of multiple non-cost-based tariffs, more akin to the monopoly
} 
(ii) cost symmetry

In the next section, we argue that within-region costs are likely to be symmetric only between entrants, and that incumbents may enjoy some cost advantage. The literature makes few predictions about the effect of introducing cost asymmetries, although Yin (2004) provides some insight within a special case, as summarised in Proposition 1b.

Proposition 1b: In the context of one-stop shopping with asymmetric costs, but where no vertical heterogeneity exists and where firms can only use two-part tariffs, equilibrium tariffs are asymmetric but remain cost-based.

(iv) symmetric brand (horizontal) preferences,

It is conceivable that brand preferences may not be symmetric because consumers may have some loyalty to, or at least face switching costs when moving away from, the incumbent. Asymmetric preferences are examined as an extension to Proposition 1 by RS (Proposition 6), as summarised below.

Proposition 1c: In the context of one-stop shopping with asymmetric horizontal preferences, $G(x)$, equilibrium tariffs are asymmetric but remain cost-based. Marginal prices remain at cost and the favoured firm optimally sets a relatively higher fixed fee.

In summary then, it appears that current theory can offer no explanation for a scenario in which firms each select a single two-part tariff, but which differs between firms in a way which cannot be attributed to asymmetries in marginal costs.

prediction (Yang and Ye 2008 and Bonatti 2008). Yang and Ye allow for non-coverage in the RS framework. In contrast to the standard approach, Bonatti allows consumers' vertical taste parameters to be supplier-specific, such that consumers who place a high marginal utility on consuming from firm $i$ also have a strong brand preference for firm $i$. Related results are also found in Yin's (2004) special set-up outlined below, where costbased pricing is shown to break down if (horizontal) transport costs become dependent upon consumption. 


\section{Tests of Theory: A Single Two-Part Tariff?}

These propositions are now tested by taking the following questions to the data. With monopoly replaced by oligopoly, do firms offer single, identical two-part-tariffs? If not, can asymmetries be explained in terms of differential marginal costs, and do incumbents set higher fixed fees? With mixed bundling of electricity and gas possible, do firms offer bundled tariffs involving a simple lump sum discount?

\subsection{Data}

We employ a database of tariff structures, observed at the individual firm level, within each of the 14 regions, at 14 six-monthly intervals, ${ }^{16}$ 1999-2005. As explained earlier, 1999-2002 was a period of consolidation, entry and exit, while 2003-5 was a period of more stable market structure with consolidation complete. Since early 2006, there has been considerable volatility in the wholesale market and firms have responded by introducing additional tracker deals or fixed-period tariffs, alongside their regular tariffs (Ofgem 2008, figure 7.2, p.75 and pp. 92-3.) Since these additional tariffs take the market beyond the setting addressed by the theoretical literature reviewed, we end our time period at December 2005. All observations refer to standard credit electricity, which was the predominant payment method for this period. ${ }^{17}$

\subsection{Pre-Liberalisation}

Prior to liberalisation, each regional incumbent offered consumers only a single twopart tariff, with a fixed fee $(F)$ per household and a single marginal price $(p)$. Figure 2 illustrates the heterogeneity of these two-part tariffs across the 14 regions, partly reflecting geographical differences in distribution cost. Clearly, these

\footnotetext{
${ }^{16}$ The sources for these data were price sheets provided in various formats by the Consumers Association and the consumer watchdog, Energywatch. June and December were selected because, for the period under consideration, tariffs rarely changed more frequently than twice a year, and such changes usually occurred in April (and occasionally October) and would have been fully recorded by June and December. Exceptionally, for 1999, the observations relate to February and October to capture the effects of market opening.

${ }^{17}$ See footnote 4. Direct debit tariffs typically offer a lump sum discount on standard credit (differing only slightly across firms and time, within the narrow range £8-15 per annum during this period). Prepayment, on the other hand, entails surcharges on standard credit. Conceivably, the provision of alternative payment methods may constitute a further deliberate form of price discrimination - although the discounts/surcharges are typically justified in publicity in terms of cost. In line with the theory above, we sidestep this issue by focusing explicitly only on discrimination in the form of nonlinear pricing, and bypass alternative payment methods. However, given the lump sum, more or less constant, nature of the direct debit discount, it is likely that all our empirical findings would remain robust across other payment methods.
} 
privatised (albeit only recently at that time) incumbent monopolists chose not to offer a menu of multiple two-part tariffs, as theory would predict for a profit maximising monopolist. Explaining such behaviour is not the purpose of the present paper, but we return to this issue in the concluding section.

Figure 2: Pre-Liberalisation Standard Credit Tariffs of Incumbents, 1998

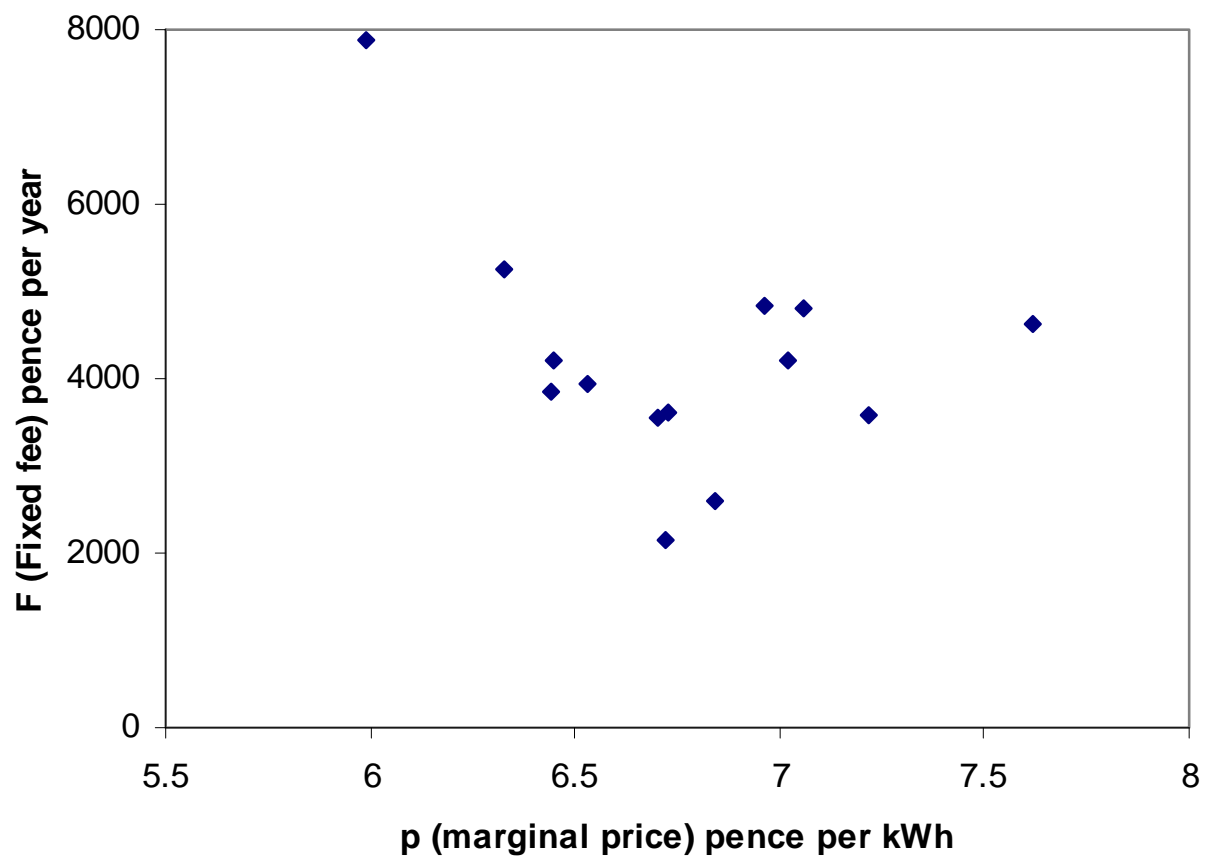

Turning to the post-liberalisation period, the data support the following five stylised facts.

Stylised Fact 1: $\quad$ Firms offered only single tariffs, and the two-part tariff was pervasive throughout.

Table 2 reveals that there are only three types of tariff structure observed: i) standard two-part tariffs, $\{p, F\}$, ii) tariffs with a zero fixed fee, but two marginal prices: $p^{H}$ $\left(p^{L}\right)$ for units below (beyond) some very low consumption threshold, $\left(X^{T}\right)$, and iii) three-part tariffs, with a positive fixed fee and two marginal prices. We interpret the second form of tariff as little more than a marketing variation on the standard twopart tariff, since $X^{T}$ was typically set at levels well below the consumption of the 
vast majority of consumers. ${ }^{18}$ Rational consumers would treat such tariffs as arithmetically 'equivalent' to a standard two-part tariff, with marginal price, $p^{L}$, and fixed fee, $F=X^{T}\left(p^{H}-p^{L}\right)$ within our theoretical context. The third, three-part, form of tariff initially accounted for a small proportion of the tariffs and had virtually disappeared by 2002. Moreover, the curvature of these tariffs was minimal, with only a small difference between $p^{H}$ and $p^{L}$.

Table 2: Incidence of Different Tariff Structures (\%)

\begin{tabular}{|c|c|c|c|}
\hline & Standard 2 part & $\begin{array}{c}\text { Equivalent 2 } \\
\text { part }\end{array}$ & 3 part \\
\hline 1999 & 82 & 6 & 12 \\
\hline 2000 & 77 & 16 & 7 \\
\hline 2001 & 78 & 14 & 8 \\
\hline 2002 & 64 & 34 & 2 \\
\hline 2003 & 65 & 33 & 1 \\
\hline 2004 & 62 & 36 & 1 \\
\hline 2005 & 63 & 37 & 0 \\
\hline total period & $\mathbf{7 0}$ & $\mathbf{2 5}$ & $\mathbf{5}$ \\
\hline
\end{tabular}

This table is based on counts at year-ends.

Stylised Fact 2: $\quad$ Firms did not set identical two-part tariffs in the typical market.

The simple scattergram of $F$ against $p$ for the pooled database Figure 3(i) reveals considerable heterogeneity between firms in their two-part tariffs, ${ }^{19}$ and the descriptive statistics reported in the first three columns of Table 3 confirm that this is true for every point in time: the standard deviation of $p$ is approximately $10 \%$ of the mean and rising through the period, and the standard deviation of $F$ is between $25 \%$ and $38 \%$ of the mean, and also rises sharply through the period. A standard analysis of variance establishes conclusively that the dominant source of this dispersion is within-region rather than between-region: the fourth and fifth columns of the table show that within-region variance accounts for between $63 \%$ and $97 \%$ of the

\footnotetext{
18 The threshold is $900 \mathrm{KwH}$ or less in $97 \%$ of observations. Interpolation within Figure 1 above suggests that only $4 \%$ of households had lower consumption than this (and many of these pay by prepayment, rather than standard credit to which these data apply).

${ }^{19}$ Hereafter, each firm's tariff is expressed in terms of just $F$ and $p$. For the 'equivalent' two-part tariffs, the 'equivalent $F$ ' is computed as described in the text; and for the three-part tariffs, $p$ is measured by whichever of $p^{H}$ or $p^{L}$ applies for the 'typical' consumer, with $X=3300$. This is invariably $p^{L}$.
} 
total variance in $p$ and $82-97 \%$ for $F$. Figure 3(ii) illustrates the extent of dispersion at the regional level, using Eastern as an example (all others regions reveal similar patterns). The fact that dispersion is prevalent within regions is important because the region is the natural definition of the market in this context.

Figure 3(i): Scatter of $F$ against $p$, Pooled over all Regions

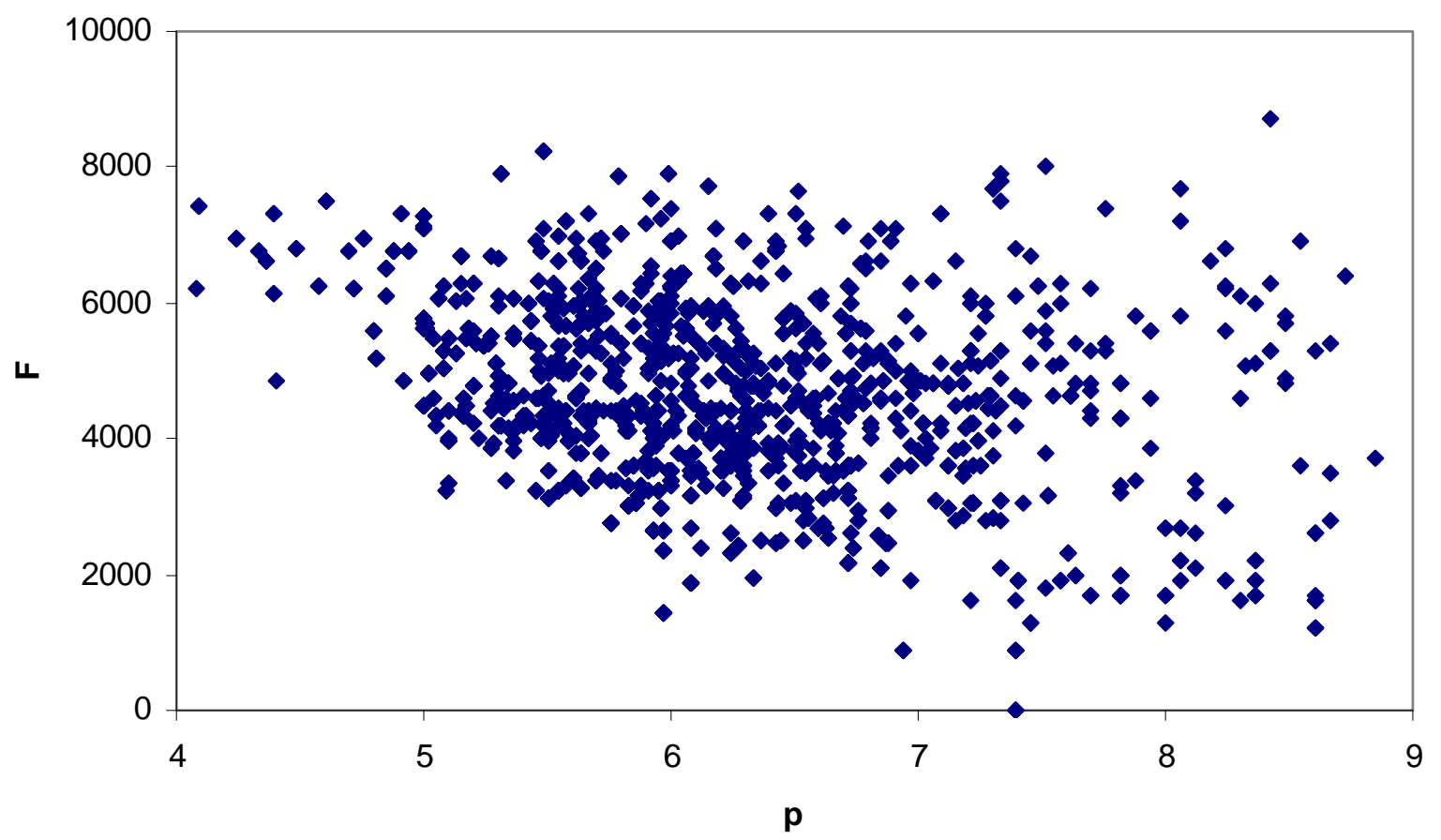


Figure 3(ii): Scatter of $F$ against $p$,for Sample Region (Eastern)

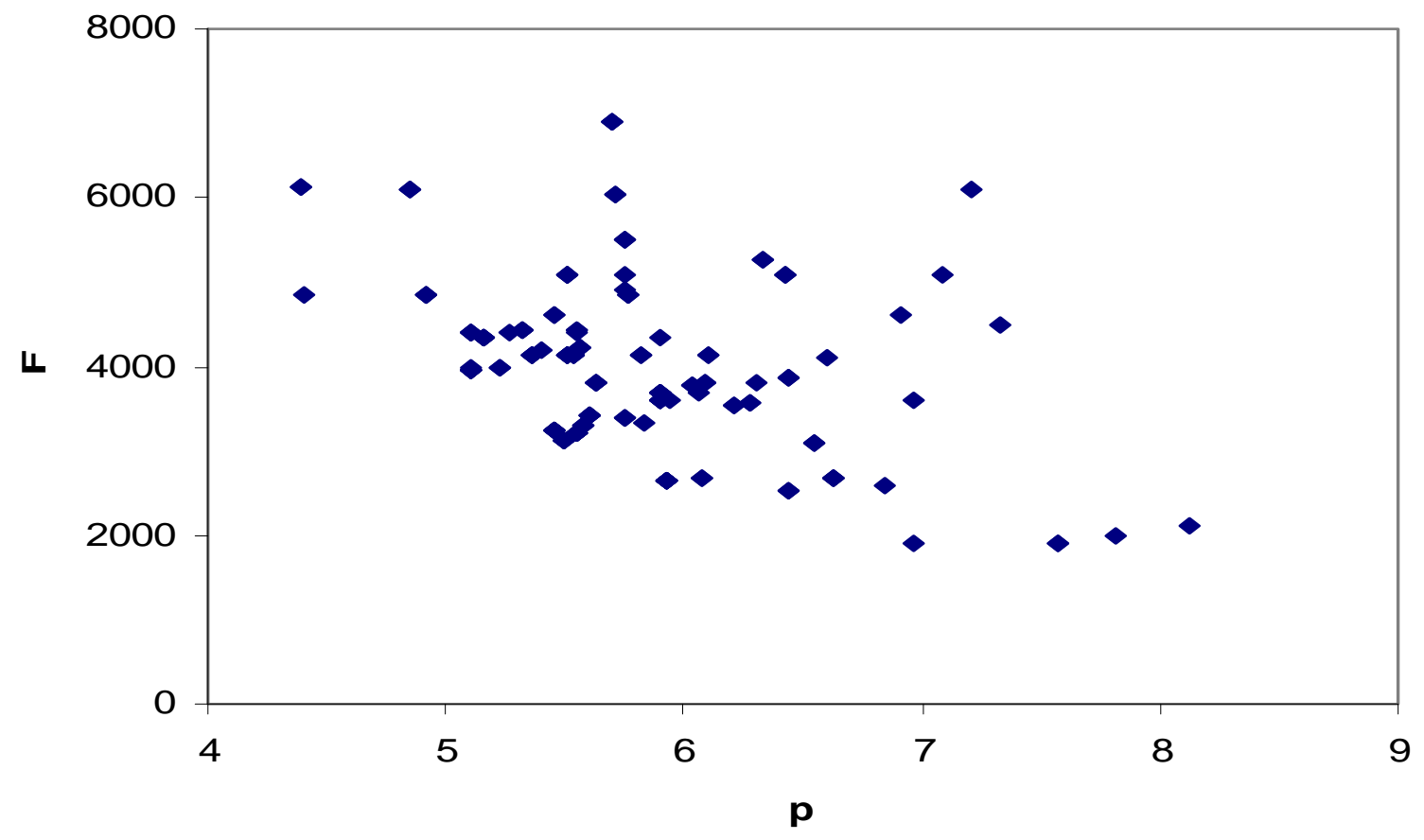

Figure 3(iii) $F$ vs $p$ : Entrants Relative to Incumbents, Scatter for Pooled Sample

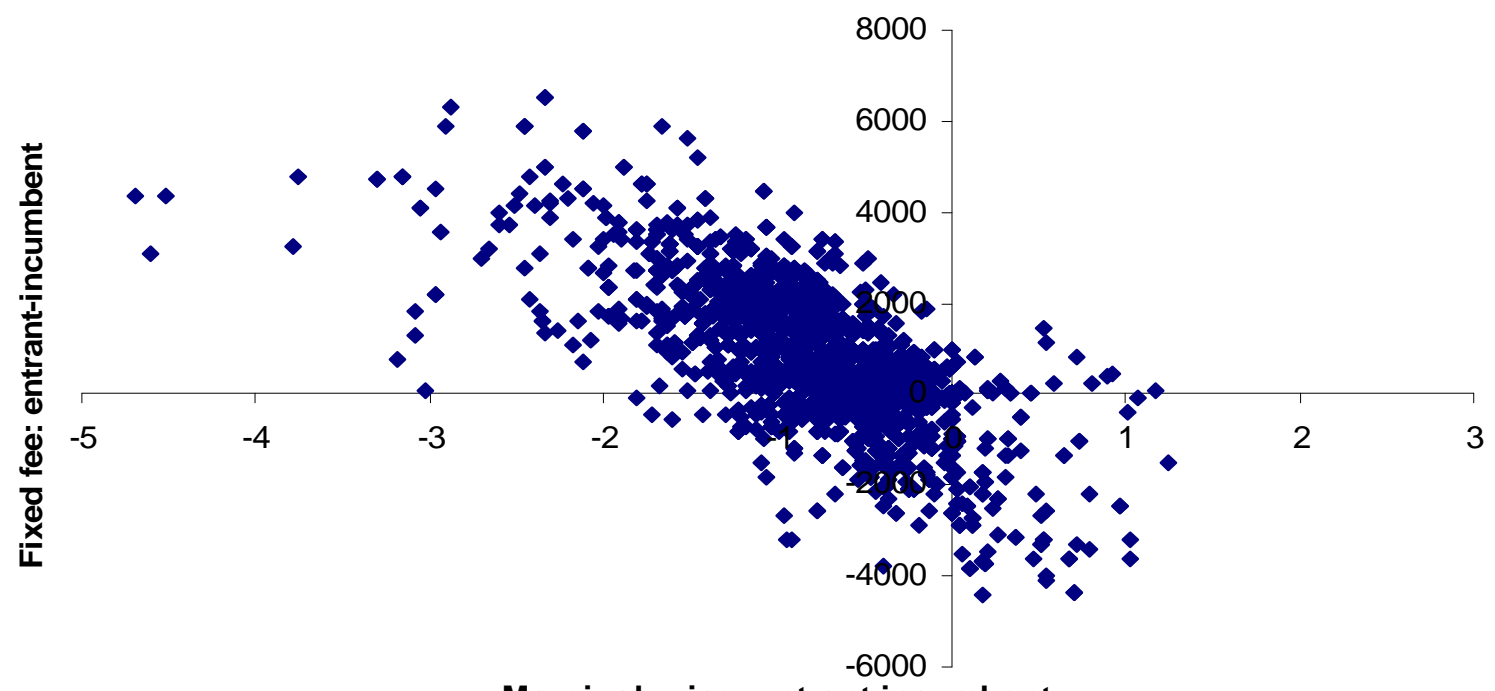

Marginal price: entrant-incumbent 
Table 3: Descriptive Statistics for $p$ and $F$

\begin{tabular}{|c|c|c|c|c|c|c|c|}
\hline & \multicolumn{3}{|c|}{ Descriptives } & \multicolumn{2}{|c|}{ Decomposition of Variance \% } & \multirow{2}{*}{$\begin{array}{l}\text { Mean Entrant- } \\
\text { Mean Incumbent }\end{array}$} & \multirow{2}{*}{$\begin{array}{l}\text { Range amongst } \\
\text { entrants }\end{array}$} \\
\hline Year & St.Dev & Mean & CoefV & Within-region & Between-region & & \\
\hline \multicolumn{8}{|c|}{ Marginal price $(p)$} \\
\hline 1999 & 0.48 & 6.26 & 0.08 & 77.8 & 22.2 & -0.48 & 1.29 \\
\hline 2000 & 0.59 & 5.96 & 0.10 & 66.0 & 34.0 & -0.59 & 1.61 \\
\hline 2001 & 0.55 & 5.81 & 0.10 & 63.2 & 36.8 & -0.84 & 1.11 \\
\hline 2002 & 0.67 & 5.84 & 0.12 & 73.3 & 26.7 & -0.85 & 1.86 \\
\hline 2003 & 0.70 & 6.06 & 0.12 & 72.2 & 27.8 & -0.94 & 1.39 \\
\hline 2004 & 0.89 & 6.79 & 0.13 & 88.1 & 11.9 & -1.11 & 2.12 \\
\hline 2005 & 1.12 & 7.70 & 0.15 & 96.6 & 3.4 & -1.32 & 2.61 \\
\hline \multicolumn{8}{|c|}{ Fixed fee $(F)$} \\
\hline 1999 & 1208 & 4761 & 0.25 & 83.1 & 16.9 & 667 & 3615 \\
\hline 2000 & 1136 & 4443 & 0.26 & 86.4 & 13.6 & 513 & 3545 \\
\hline 2001 & 1065 & 4429 & 0.24 & 82.8 & 17.2 & 459 & 2929 \\
\hline 2002 & 1137 & 4597 & 0.25 & 90.0 & 10.0 & 534 & 3397 \\
\hline 2003 & 1424 & 4602 & 0.31 & 97.3 & 2.7 & 1050 & 3814 \\
\hline 2004 & 1822 & 4799 & 0.38 & 91.4 & 8.6 & 1332 & 4888 \\
\hline 2005 & 1958 & 5123 & 0.38 & 89.3 & 10.7 & 1372 & 5447 \\
\hline
\end{tabular}

Note: This table describes the data only at year-ends. 
Table 4: Breakdown of Retailers' Costs, 2003

\begin{tabular}{|l|c|l|c|}
\hline & $\begin{array}{c}\% \text { of } \\
\text { total }\end{array}$ & \multicolumn{1}{|c|}{ Sources of variability } & $\begin{array}{c}\text { Firms which might enjoy cost } \\
\text { advantages within region }\end{array}$ \\
\hline Generation & 30 & $\begin{array}{l}\text { Firms with integrated generation and retail } \\
\text { activities (mainly incumbents and } \\
\text { majorsaway) can hedge volatile wholesale } \\
\text { prices more cheaply. }\end{array}$ & $\begin{array}{c}\text { Firms which are vertically } \\
\text { integrated }\end{array}$ \\
\hline $\begin{array}{l}\text { Transmission } \\
\text { including } \\
\text { systems losses }\end{array}$ & 4 & $\begin{array}{l}\text { These vary between regions and suppliers, } \\
\text { depending on the location of generation } \\
\text { relative to the market, but they will not vary } \\
\text { within regions }\end{array}$ & - \\
\hline $\begin{array}{l}\text { Distribution } \\
\text { including } \\
\text { systems losses }\end{array}$ & 34 & $\begin{array}{l}\text { Distribution tariffs vary significantly between } \\
\text { regions, but not at all within regions. }\end{array}$ & - \\
\hline Metering & 9 & - & $\begin{array}{l}\text { Incumbents may have marketing/advertising } \\
\text { advantage; entrants must overcome inertia } \\
\text { and lack of brand name. }\end{array}$ \\
\hline $\begin{array}{l}\text { Retail excluding } \\
\text { metering }\end{array}$ & 15 & Common across firms \\
\hline VAT \& sundries & 9 & Comments \\
\hline
\end{tabular}

Source: Cornwall (2008), 2001-02 OFGEM distribution tariffs and authors' estimates.

Stylised Fact 3: The asymmetries between firms' two-part tariffs cannot be explained purely in terms of differences in costs.

There are few published data on costs at the individual firm level, so evidence for this fact is necessarily indirect, but nevertheless conclusive. Retailers in this industry face five types of marginal cost (Table 4), and while these may lead to significant cost differences between regions (notably in distribution costs), within-region variation in marginal costs is likely to be small. Indeed, the only likely sources of marginal cost asymmetries within a given region derive from generation and retail costs, and these are likely to favour the incumbents relative to entrants. Despite this however, our data show that incumbents typically set a higher marginal price than entrants. This is shown in Figure 3(iii), which reframes Figure 3(i), by plotting the differential between each entrant's fixed fee and the incumbent's fixed fee, against the gap between the entrant's and incumbent's marginal price. The vast majority of observations lie in the top left quadrant, indicating that most entrants charge a lower marginal price and higher fixed fee than does the relevant incumbent. The sixth column of Table 3 quantifies the typical difference between entrants' and

20 A common clearing market presented all suppliers with similar marginal generation costs, even after the closure of the Electricity Pool in 2001. 
incumbents' marginal prices over time: as a proportion of mean price, this is about $10-15 \%$, and rising through the period. The last column of Table 3 also shows that there is typically a large range of marginal prices amongst entrants in any given region. Again, there is no cost-based explanation for this, as we would expect entrants to share a similar cost structure.

The evidence of Table 3 and Figures 3 also leads immediately to:

Stylised Fact 4: $\quad$ Contrary to Proposition 1c, incumbents do not exploit potential incumbency advantages by setting relatively higher fixed fees. In fact, the reverse is true.

Finally, turning to the tariffs for bundled electricity and gas:

Stylised Fact 5: $\quad$ The predominant (but not unanimous) form of dual fuel discount is a relatively small lump sum.

Comparable data on these discounts for the Majorsaway and British Gas are available from 2002 onwards, and this provides an opportunity to test Proposition 2. Three of these six firms offered a lump sum discount of between $£ 10$ and $£ 15$ throughout, one offered no discount, one used a lump sum but appears to have later switched to a proportionate discount, and one offered a proportionate discount throughout. In all cases this discount amounted to $1.5-3 \%$ of the typical bill. This is broadly in keeping with the results of Armstrong and Vickers (2008), but the coexistence of proportionate and zero discounts suggests that more evidence is warranted. For the remainder of the paper, we focus on electricity-only tariffs.

\section{Tariff Heterogeneity}

Some of the findings in the previous section - the prevalence of single, two-part tariffs and lump-sum bundling discounts - are consistent with theory, but the widespread non-cost-related tariff asymmetries between firms within regional markets are not. This section identifies some systematic features of these asymmetries. 
For these purposes it is useful to summarise each two-part tariff with a single statistic. We choose the ratio of a tariff's fixed fee to its marginal price, referred to hereafter as the tariff's weighting, $W$. Tariffs with higher weighting rely more on the fixed fee than the marginal price to raise revenue, and, ceteris paribus, will be more attractive to high volume consumers.

$$
W=(F / p)
$$

As shown above, there is considerable dispersion in the two components of $W$, and this dispersion is accentuated by a strong inverse correlation between the two (typically between -0.4 and -0.6 ). Across the sample, $W$ has a mean and standard deviation of 770 and 265 respectively, with an approximately normal distribution. ${ }^{21}$ Figures $4 a, b$ and c demonstrate some further features of $W$.

Figure $4 a$ shows that the average tariff weighting remained fairly stable during the first part of the period, before declining steadily in the second part. More strikingly, the asymmetry in firms' tariffs, as measured by the standard deviation of $W$, rose dramatically in the second part of the period after a period of initial stability. ${ }^{22}$ Figure $4 \mathrm{~b}$ explores this dispersion by reporting the results of decomposing the variance of $W$ both by region and by firm. ${ }^{23}$ Decomposing by region, the within-region component clearly dominates: it always accounts for the major share (about 90\%), and this rises further in the later part of the period. This confirms the implications of the similar decompositions for $p$ and $F$ in the previous section. Although there are non-trivial differences between regions (probably due to differential distribution costs), it is heterogeneity between firms within-regions which is the main cause of dispersion. Alternatively, decomposing the variance by firm, it is the between-firm component which dominates, but less heavily. This is not surprising since withinregion and between-firm variances reflect two sides of the same coin. ${ }^{24}$ However, the fact that within-region variation accounts for a larger share than between-firm adds a further insight. It implies that firms do not simply apply the same tariff

\footnotetext{
${ }^{21}$ This implies that on average, the fixed fee accounts for $13 \%$ of a high volume consumer's typical bill, as opposed to $20 \%$ for a medium volume consumer, or $30 \%$ for a low volume consumer.

${ }^{22}$ This growth is even more marked if dispersion is measured by the coefficient of variation.

23 The figure only displays the dominant component in each case.

${ }^{24}$ In the extreme case where all firms set the same $W$ in all regions, but the value of $W$ differs between firms, within-region and between-firm variance would be identical, and would both account for $100 \%$ of the total variance in their respective decompositions.
} 
nationwide across all regions - instead, they employ at least some degree of 'regionspecificity'.

\subsection{Entrants versus Incumbents}

One obvious explanation for some region-specificity has been implied already by the finding from Table 3, that incumbents typically select higher marginal prices and lower fixed fees, and therefore lower $W$, than do entrants. Remembering that most firms in this industry are incumbents in some regions but entrants in others, this is an obvious source of within-firm heterogeneity.

Figure 4a: Mean and Standard Deviation $W$ over time for Pooled Sample

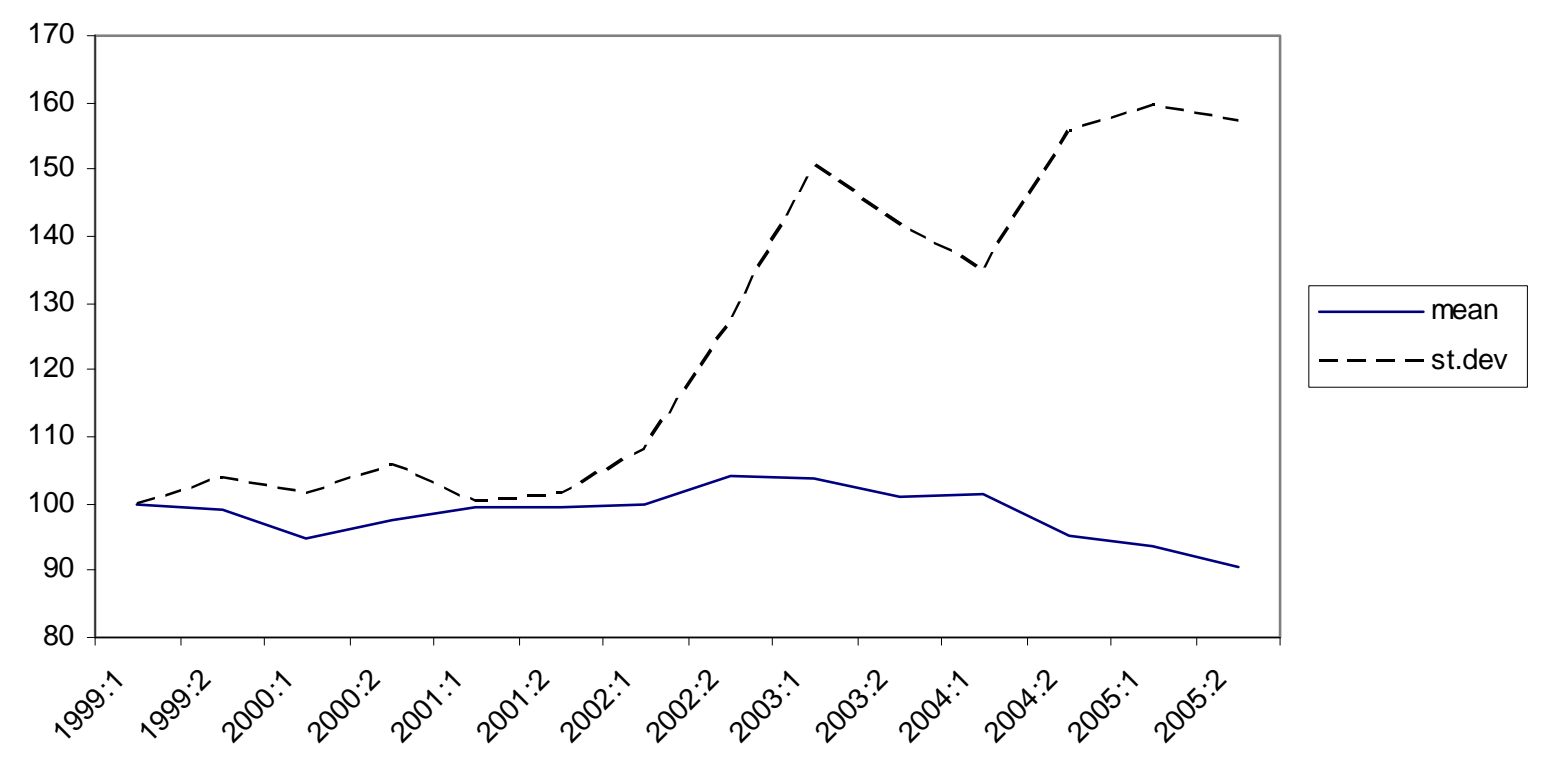


Figure 4b: Decomposition of Variance of $W$ over time, by Firm and Region

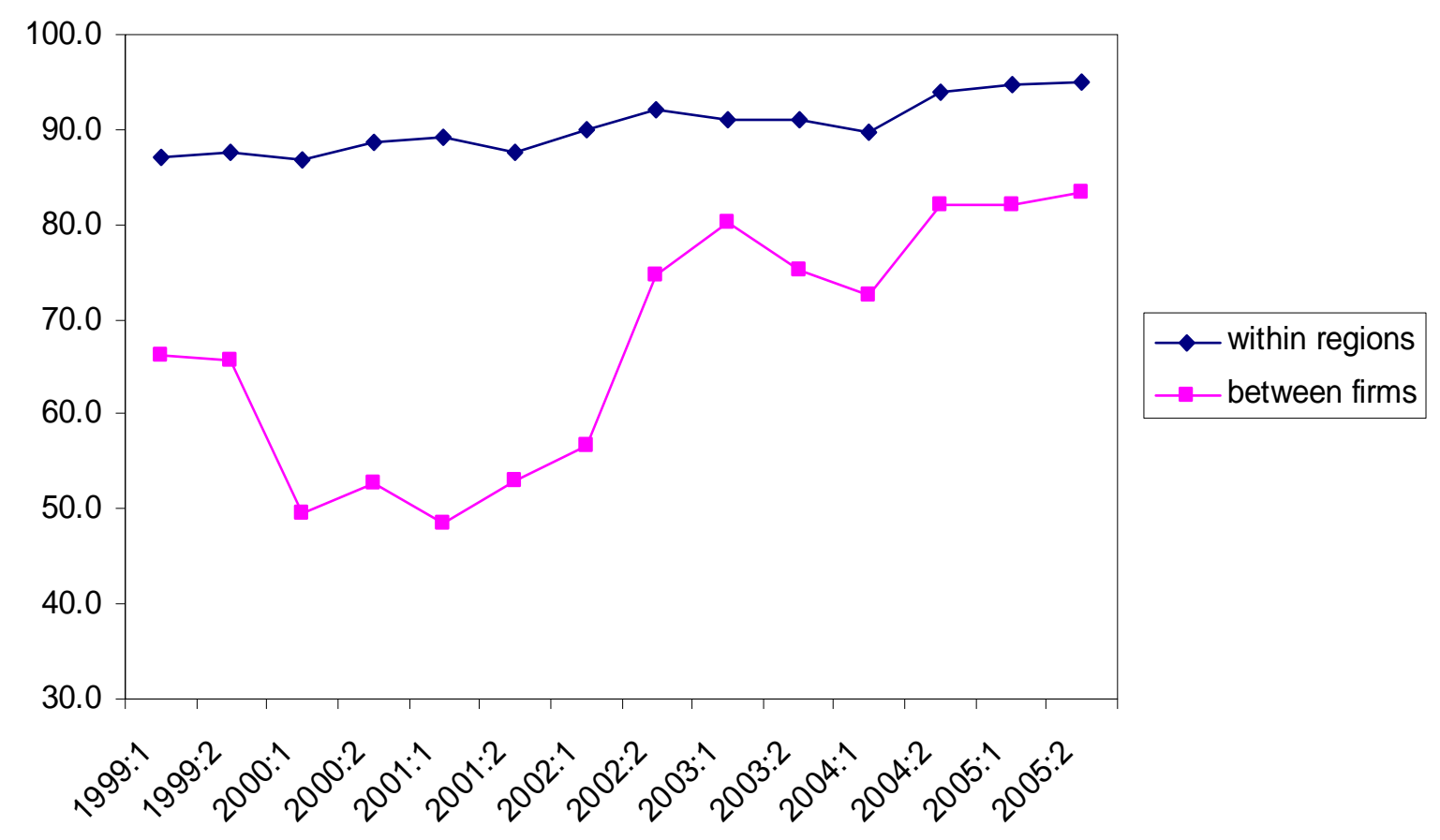

Figure 4c: Mean $W$ - Entrants versus Incumbents

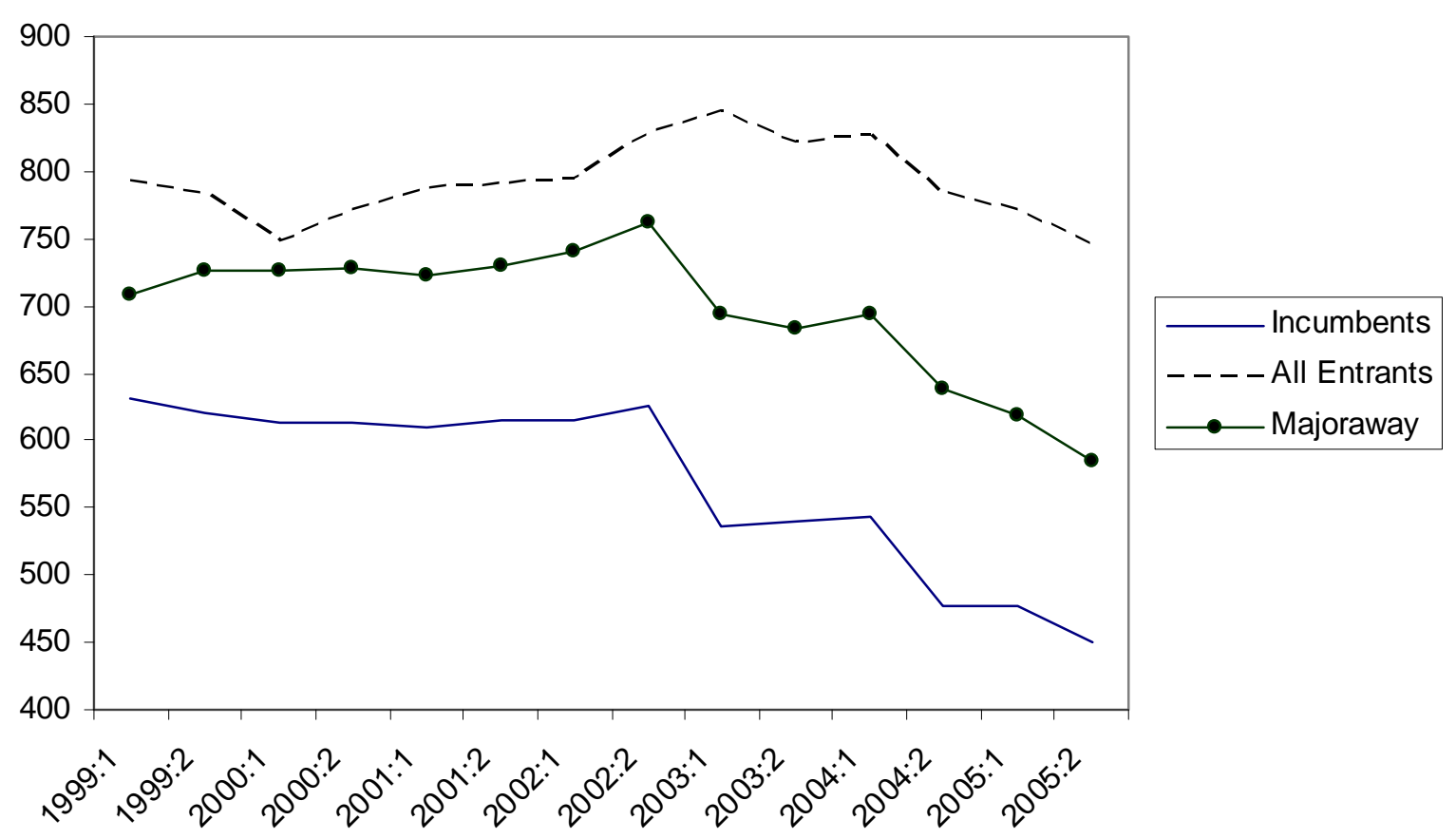

Within-firm heterogeneity is confirmed in Figure 4c which depicts the time paths of the mean tariff weighting for incumbents, entrants and 'Majorsaway' (averaged across all regions). In both cases, there is a persistent and significantly positive 
differential between entrants and incumbents, ${ }^{25}$ and this widens in the second part of the time period. In the case of the Majorsaway, this has an important additional interpretation: because these firms are the incumbents in some regions but entrants in others, it refers not only to the differences between entrants and incumbents within markets, but also to the differences between the weightings chosen by firms in their ‘home' (incumbent) markets and in their 'away' (entrant) markets. This leads to:

\section{Stylised Fact 6: $\quad$ Entrants typically set higher tariff weightings than incumbents.}

Stylised Fact 7: $\quad$ Majors typically set higher tariff weightings when playing the role of entrant rather than the incumbent.

The other striking feature of all three parts of Figure 4 is the contrast between the early (1999-2002) and later parts (2003-5) of the period. Recall that until 2002, there were important structural changes arising from the acquisitions of the Minimajors by the Majors and the entry/exit of smaller Independents. Moreover, incumbents were still subject to price-cap regulation. With this consolidation completed and regulation removed, it appears that tariff weightings became even more dispersed. While it is impossible to establish a direct causality with the data at our disposal, ${ }^{26}$ the possibility of a structural break is explored econometrically below.

\subsection{Heterogeneity amongst Entrants}

This section examines heterogeneity amongst entrants. Given the absence of any theoretical explanation for such tariff heterogeneity, we do not attempt to specify and estimate a structural model. Instead, we seek to identify how far this source of

\footnotetext{
${ }^{25}$ In both cases, the mean differential is significantly different from zero at the $99 \%$ level at each point in time.

${ }^{26}$ On the potential impact of the removal of regulation, the previous literature provides an equivocal message. In the theoretical regulation literature, two papers consider the potential effects of price caps on average revenue per unit (the form of regulation imposed in this case.) Bradley and Price (1988) show that this form of regulation should induce a monopolist to raise the least price-responsive element of its tariff. Assuming, not unreasonably, that this is the fixed fee, the implication is that the removal of regulation should induce the monopolist to lower its fixed fee (and thus lower $W$ ). Armstrong, Cowan and Vickers (1995, Corollary 1 ) establish a qualitatively similar result: a regulated monopolist will serve sufficiently high-type consumers with larger quantities than is efficient, using a marginal price less than marginal cost. So in both cases, the implication is that the removal of regulation should have lead to lower tariff weightings - as is observed here. However, both papers are confined to regulated monopolists rather than oligopoly. The empirical literature, on the other hand, suggests that the regulation was non-binding. By the time that regulation was removed, OFGEM (2001) reports that all but three incumbents were charging less than permitted under the price cap by between 0.4 and 2.2\%; and Giulietti and Waddams Price (2005) find that firms had not increased their fixed fees in response to the incentives presented by the price cap. Therefore, we leave open the issue of whether deregulation in 2002 was the cause of increased dispersion.
} 
heterogeneity can be identified with robust systematic differentials between different entrants. To do this, we fit a simple disaggregated equation on firm-level tariff weightings for the full sample of entrants. For each market (region) $j$ at time $t$, suppose that entrant $k, \forall k=1, \ldots(n-1)$, sets its tariff weighting, $W_{j t}^{k}$, relative to the incumbent's, $W_{j t}^{I}$, such that ${ }^{27}$

$$
W_{j t}^{k}-W_{j t}^{I}=\alpha^{k}+\beta W_{j t}^{I}+\varepsilon_{j t}^{k}
$$

Results are shown in Table 5.

${ }^{27}$ This relationship can be derived from linear best-response functions in weightings (see appendix). 
Table 5: Entrant Tariff Weightings Relative to Incumbent $\left(W^{E}-W^{I}\right)^{*}$

\begin{tabular}{|c|c|c|c|c|c|}
\hline $\begin{array}{l}\text { Explanatory } \\
\text { variables }\end{array}$ & I & II & III & IV & V \\
\hline Incumbent $\left(W^{I}\right)$ & $-0.847(0.035)$ & $-0.839(0.032)$ & $-0.796(0.033)$ & $-0.788(0.036)$ & $-0.784(0.035)$ \\
\hline Intercept* & $701.6(20.8)$ & $609.4(18.5)$ & $401.0(22.9)$ & $459.5(21.7)$ & $457.0(21.1)$ \\
\hline BritishGas & & $245.8(8.5)$ & $429.5(12.7)$ & $378.9(10.5)$ & $441.7(23.7)$ \\
\hline Independent & & $224.5(17.6)$ & & & \\
\hline Minimajorsaway & & $59.2(10.5)$ & & & \\
\hline \multicolumn{6}{|l|}{ Majorsaway } \\
\hline EDF & & & $137.0(15.6)$ & $27.5(9.4)$ & 42.9 (11.8) \\
\hline NPower & & & $342.7(17.0)$ & 386.7 (12.6) & $402.1(14.5)$ \\
\hline SSE & & & $-0.6(16.3) \dagger$ & $-63.4(15.9)$ & $-47.3(14.6)$ \\
\hline Scottish Power & & & $428.6(16.0)$ & $327.4(13.9)$ & $342.8(15.8)$ \\
\hline \multicolumn{6}{|l|}{ Minimajorsaway } \\
\hline Northern Electric & & & 314.6 (43.6) & $251.9(42.5)$ & $267.4(44.4)$ \\
\hline Norweb & & & $264.5(16.7)$ & $201.5(11.9)$ & $216.9(13.6)$ \\
\hline Seeboard & & & $216.2(19.7)$ & $154.2(16.8)$ & $168.5(19.4)$ \\
\hline Swalec & & & $32.1(23.7) \dagger$ & $-30.9(21.9) \dagger$ & \\
\hline Sweb & & & $167.1(24.7)$ & $103.9(23.1)$ & $119.3(22.2)$ \\
\hline TXU & & & $180.7(21.9)$ & $118.7(19.6)$ & $133.1(19.6)$ \\
\hline Yorkshire & & & $371.4(19.0)$ & $308.4(14.8)$ & $323.8(15.5)$ \\
\hline \multicolumn{6}{|l|}{ Independents } \\
\hline Atlantic & & & $312.1(18.0)$ & $253.9(18.0)$ & $264.9(17.7)$ \\
\hline Basic & & & $684.1(28.7)$ & $396.2(35.0)$ & $411.6(35.7)$ \\
\hline Amerada & & & $224.3(14.5)$ & $161.3(11.8)$ & $176.7(14.1)$ \\
\hline Independent & & & $334.4(18.9)$ & $271.4(16.7)$ & $286.8(16.3)$ \\
\hline Northern Energy & & & $20.5(29.1) \dagger$ & $-42.5(27.0) \dagger$ & \\
\hline \multicolumn{6}{|c|}{ Interacted with post-2002 dummy } \\
\hline$W^{I}$ & & & & $-.014(.030) \dagger$ & \\
\hline British Gas & & & & $-16.9(24.3) \dagger$ & \\
\hline EDF & & & & $105.6(21.3)$ & $98.7(13.7)$ \\
\hline NPower & & & & $-219.9(33.9)$ & $-227.4(29.7)$ \\
\hline Powergen & & & & $-125.9(27.0)$ & $-117.8(23.4)$ \\
\hline SSE & & & & $7.4(28.4) \dagger$ & \\
\hline Scottish Power & & & & $84.3(32.0)$ & $78.0(26.8)$ \\
\hline Basic & & & & $393.2(45.3)$ & $386.9(42.6)$ \\
\hline $\mathrm{R}^{2}$ & 0.298 & 0.404 & 0.674 & 0.723 & 0.723 \\
\hline $\mathrm{F}$ & & 308.4 & 83.0 & 4.3 & \\
\hline
\end{tabular}

* Notes: $N=1850$; Standard errors are shown in parentheses; all coefficient estimates are significant at the 1\% level except those marked as $\dagger$ and shown in italics, which are not significant at the 5\% level. Default: Majorsaway (II) or Powergen (III-V); $W^{I}$ is instrumented as described in the text; equations are estimated in STATA employing the robust correction. The reported F statistics allow us to reject the hypotheses that: the firm type variables in II are homogeneous; the individual firms in each type in III are homogeneous; and the coefficients of the estimated model are identical in the two sub-periods in IV (confirming the existence of a structural break).

The equation is first estimated (in column I) abstracting from any systematic heterogeneity amongst entrants, i.e. with $\alpha^{k}=\alpha \forall k$. This is extended (in II) to include fixed effects for each of the four entrant-types; and then (in III) to allow for 
different fixed effects for all entrants individually, $\alpha^{k} \forall k=1, \ldots(n-1)$. Equations (IV) and $(\mathrm{V})$ test for a possible structural break, midway through the period, coinciding with the completion of firm consolidation and the final deregulation of the industry, described above.

Throughout, the equation is estimated using a vector of variables to instrument the incumbent's tariff weighting, $W^{I}$. While each of these instruments is a plausible determinant of $W^{I}$, none should have any obvious correlation with the magnitudes of the entrant-incumbent differential. The instruments are a wholesale price index of electricity $\left(\mathrm{WP}^{28}\right)$, the pre-liberalisation tariff weighting in region j (INITIAL_W), and fixed effects by identity of the incumbent in $\mathrm{j}$ (INC_IDENTITY). WP is included as it is a major component of the retailers' marginal costs; INIT_W is included to represent broad differences between regions in costs and demand factors - these should be the main reasons why incumbents employed weightings which differed between regions before the advent of competition; and INC_IDENTITY allows for differences between incumbents in their home market strategies. The latter should also capture any shifts in incumbent strategies in those regions where the identity of incumbent changes because of acquisition. Hausman-Wu tests reject the null hypothesis of exogeneity of the incumbent's weighting at the $95 \%$ level in all five equations. All equations are estimated using a cluster estimator, with observations clustered by region at each point in time, to allow for the likelihood of a common component in the disturbance term (Wooldridge, 2002).

Equation (I) establishes two findings which are robust across all five equations. First, the $\beta$ coefficient is negative but significantly smaller than (absolute) unity. This confirms that entrants employ tariff weightings which are sensitive to the magnitude of the incumbent's weighting, but suggests 'incomplete adjustment', in the sense that the differential becomes larger (smaller) when the incumbent lowers (raises) its weighting. Second, the intercept confirms the pervasive tendency for entrants to set higher tariff weightings than the incumbent: the absolute size of the differential depends on the magnitude of $W^{I}$, but it is positive (206) at mean $W^{I}$ and

\footnotetext{
${ }^{28}$ Constructed from data published in Quarterly Energy Prices (e.g. 2008, Department of Energy and Climate Change).
} 
for $95 \%$ of all sample observations on $W^{I}$. However, crucially, the overall fit reveals that over $70 \%$ of the dispersion in tariff weightings remains unexplained:

Stylised Fact 8: $\quad$ There is considerable heterogeneity amongst entrants in their tariff weightings.

Equations (II) and (III) explore this residual heterogeneity by allowing for differences between types of entrant and by individual firms. With Majorsaway used as the default category, equation (II) reveals systematic differences between the four firm types, with British Gas and Independents setting the highest tariff weightings (not significantly different from each other), and the Majorsaway the lowest. Although inclusion of these firm-types significantly raises the overall fit, there is clearly still considerable within-type heterogeneity. Once fixed effects for each firm individually are included, in equation (III), the unexplained heterogeneity is significantly further reduced. Two-thirds of the variance is explained purely by including fixed effects for the identities of individual entrants. This suggests that a sizeable majority of entrant heterogeneity can be explained by simple firm differences which appear to be robust across the 14 different regions and over the 14 different time points.

Stylised Fact 9: $\quad$ Much of the heterogeneity between entrants is systematic across regions and over time.

Finally, to explore the increased heterogeneity post-2002, as revealed in figures 4a)c), equation IV allows coefficients to differ between the two sub-periods 1999-2002 and 2003-5. The $F$ test reported under equation (IV) confirms the existence of a structural break, and equation (V) re-estimates (IV) excluding all insignificant variables.

To assist interpretation of the results in equation (V), Table 6 employs the estimated coefficients to compute the predicted differential between each entrant and the incumbent, in each sub-period, evaluated at sample mean values of $W^{I}$. This serves two purposes. First, it illustrates the main sources of heterogeneity between entrants: only four of the eighteen entrants opted for a tariff weighting which is typically lower than the incumbent's, and even these are only marginally so. 
Amongst the other fourteen, the largest differentials are set by British Gas, most of the Independents and two of the Majorsaway.

Second, Table 6 helps to clarify the (arithmetic) causes of the increase in heterogeneity after 2003. As can be seen, the differential increases for British Gas, three of the Majorsaway and the (one remaining) independent. Summing across all entrants, there is a near doubling in both the aggregate mean differential and its standard deviation: on average, entrants distanced themselves further from incumbents, and dispersion amongst entrants increased. In addition, because of the significant exit by 2002 , there is also a composition effect which contributes to the measured heterogeneity, because the exitors tended to exhibit lower differentials in the first sub-period. To quantify this effect the final two rows show the changes in the mean differential and its standard deviation for the set of surviving firms only. This reduces, but by no means removes, the increases between the two subperiods; the composition effect is contributory, but, even controlling for this, there remains a widening of the differential, vis-à-vis incumbents, for the surviving entrants.

Stylised Fact 10: Tariff heterogeneity increased over time because of three effects: (i) increased asymmetry between entrants and incumbents; ii) increased asymmetry amongst entrants; and iii) the exit of entrants whose tariff weightings were initially close to the incumbent's. 
Table 6: Mean Predicted Entrant-Incumbent Differentials* $\left(W^{E}-W^{I}\right)$

\begin{tabular}{|lrr|}
\multicolumn{1}{c}{$1999-2002$} & $2003-5$ \\
\hline BritishGas & 340 & 410 \\
\hline Majorsaway & & \\
NPower & 360 & 203 \\
Scottish Power & 301 & 449 \\
EDF & 1 & 170 \\
Powergen & -42 & -89 \\
SSE & -89 & -19 \\
Type Mean & 106 & 143 \\
\hline
\end{tabular}

\begin{tabular}{|lrc|}
\hline Minimajorsaway & & \\
Seeboard & 126 & n.a. \\
Yorkshire & 281 & n.a. \\
Northern Electric & 225 & n.a. \\
Norweb & 175 & n.a. \\
TXU & 91 & n.a. \\
Sweb & 77 & n.a. \\
Swalec & -42 & n.a. \\
Type Mean & 133 & n.a. \\
\hline
\end{tabular}

\begin{tabular}{|c|c|c|}
\hline \multicolumn{3}{|l|}{ Independents } \\
\hline Basic & 370 & 827 \\
\hline Independent & 245 & n.a. \\
\hline Atlantic & 222 & n.a. \\
\hline Amerada & 135 & n.a. \\
\hline Northern Energy & -42 & n.a. \\
\hline Type Mean & 186 & 827 \\
\hline Aggregate Mean & 151 & 279 \\
\hline Aggregate St. Dev. & 147 & 290 \\
\hline \multicolumn{3}{|l|}{ Surviving firms only } \\
\hline Mean & 177 & 279 \\
\hline St. Dev. & 194 & 290 \\
\hline
\end{tabular}

* Evaluated at mean $W^{I}$ (618 in 1999-2002, 528 in 2003-5), using coefficient estimates from equation $V$, Table 6. n.a. implies that the firm had exited by the start of the second sub-period. 


\section{Discussion and Conclusions}

This paper has tested the findings of some recent developments in the theory of oligopolistic nonlinear pricing. In line with these predictions, we have found that suppliers in the newly liberalised British electricity market offered single two-part electricity tariffs and simple lump sum discounts for bundled electricity and gas tariffs. However, contrary to current theory, suppliers vary considerably in their chosen tariffs within a given market in ways that cannot be attributed to marginal cost differences. Further examination of heterogeneity amongst firms in any market reveals three key facts: 1) relative to incumbents, entrants tend to select two-part tariffs with higher tariff weightings (higher fixed fees and lower marginal prices); 2) despite likely symmetric costs amongst, there is a systematic heterogeneity in their tariff weightings across different types of entrants and between individual entrants; and 3) these asymmetries increased over time.

To our knowledge, there is no current theoretical explanation of how these observed non-cost-based tariff asymmetries can occur in an oligopolistic equilibrium. Part of the answer might lie in the institutional details of this particular market. Preliberalisation, governmental pressure on incumbents to serve low-income consumers may have led to a downward distortion in their tariff weightings, and this may have persisted into the post-liberalisation era due to price regulation in the early years and potential consumer resistance. However, this fails to explain the systematic and increasing tariff heterogeneity between different entrants. We identify three potential explanations of heterogeneity as directions for future research.

First, there is a conflict between the assumed one-shot, one-stage nature of competition in the theory and the observed repeated multi-market interaction in this case. This leads to the question, could the observed heterogeneity result from collusive forces? If the level of interaction were sufficient to foster collusion, the set of market tariffs would imitate a monopolist's optimal menu of two-part tariffs. Such a menu may be well approximated by a small, finite number of tariffs and so a collusive outcome could be consistent with each supplier offering a different single two-part tariff. Alternatively, even in a non-cooperative setting, could firms have the incentive to differentiate their tariff weighting so as to each appeal to a different group of 
consumers (identified by usage intensity)? This possibility resonates with the work of Champsaur and Rochet $(1989,1990)$, in which they demonstrate, in the parallel setting of quality, rather than quantity, discrimination, how similar incentives can prompt duopolists to select asymmetric quality levels and prices. Under a specific functional form, this incentive is so strong that each firm picks only a single, asymmetric quality level (with asymmetric price). While it is inappropriate to transfer this logic directly to a setting of quantity discrimination, because suppliers cannot commit to marginal prices in the same way as they can to product quality, the intuition is appealing, especially in the context of the multi-market contact which we observe for electricity where firms may have the opportunity to develop reputations or signal their intentions. ${ }^{29}$

Second, the assumption that tariffs can be implemented without cost may not be valid in practice. Miravete (2007) shows that monopolists in the early US cellular telephone industry could extract $95 \%$ of the potential profits available from a full menu of optimal tariffs through the use of only a single two-part tariff. The existence of small costs of tariff development or implementation could therefore help explain why such monopolies chose to offer only a small number of tariffs. Such costs would also help explain why, in the present case, we observed the incumbent monopolists using only using single two-part tariffs pre-liberalisation, and could offer an alternative explanation for the existence of single tariffs under oligopoly postliberalisation.

Third, there is a clear conflict between the theoretical assumption of fully informed rational consumers and the behaviour of consumers observed in practice (e.g. Wilson and Waddams Price 2008). Understanding how consumer information and rationality are bounded, and how this impacts on firms' tariff choices, remains an open and difficult question, but one which deserves further study.

\footnotetext{
${ }^{29}$ Busse (2000) provides related evidence that suggests multi-market contact may enable suppliers to signal their intention to set higher tariffs (across all levels of consumption) by pricing identically across multiple-regions.
} 


\section{Appendix}

Equation (2) can be derived from a set of underlying best response functions in tariff weightings. In any given market (region) $j$ at time $t$, suppose the incumbent, $I$, and the (n-1) entrants, $1, \ldots n-1$, set their tariff weightings according to the following $n$ equations.

$$
\begin{aligned}
& W_{j t}^{I}=a_{0}+c \sum_{k=1}^{n-1} W_{j t}^{k}+u_{j t}^{0} \\
& W_{j t}^{1}=\left(a_{0}+a_{1}\right)+b W_{j t}^{I}+c \sum_{k=2}^{n-1} W_{j t}^{k}+u_{j t}^{1} \\
& W_{j t}^{2}=\left(a_{0}+a_{2}\right)+b W_{j t}^{I}+c \sum_{k=1, k \neq 2}^{n-1} W_{j t}^{k}+u_{j t}^{2} \\
& \cdots \\
& W_{j t}^{n-1}=\left(a_{0}+a_{n-1}\right)+b W_{j t}^{I}+c \sum_{k=1}^{n-2} W_{j t}^{k}+u_{j t}^{n-1}
\end{aligned}
$$

Heterogeneity is allowed between the firms by permitting $a_{0} \neq a_{1} \neq \ldots \neq a_{n-1} \neq 0$, and no restrictions are placed on the values of $b$ or $c$. Subtracting (A0) from each of $(\mathrm{A} 1), \ldots(\mathrm{A} n-1)$ then yields $\left(2^{*}\right)$, which parallels equation $(2)$ in the text.

$$
W_{j t}^{k}-W_{j t}^{I}=\left(\frac{a_{k}}{1+c}\right)+\left(\frac{b-c}{1+c}\right) W_{j t}^{I}+\left(\frac{u_{j t}^{k}-u_{j t}^{0}}{1+c}\right) \quad \forall k=1, \ldots(n-1)
$$

For estimation purposes, this implies the use of i) entrant-specific fixed effects, ii) instrumental variables, as OLS will yield biased estimates due to the presence of $u^{0}$ in the disturbance term and iii) clustering, due to the presence of $u^{0}$ in all the disturbance terms within a given region. 


\section{References}

Armstrong M. (2006) "Recent Developments in the Economics of Price Discrimination" in "Advances in Economics and Econometrics: Theory and Applications, Ninth World Congress of the Econometric Society, Volume II", Chapter 4, Blundell, Newey and Persson (eds), Cambridge University Press

Armstrong, M., Cowan, S. and Vickers, J. (1995) "Nonlinear Pricing and Price Cap Regulation" Journal of Public Economics vol.58 p.33-55

Armstrong, M. and Vickers, J. (2001) "Competitive Price Discrimination" RAND Journal of Economics vol. 32 p.579-605

Armstrong, M. and Vickers, J. (2006) "Competitive Nonlinear Pricing and Bundling" University of Oxford, Department of Economics Discussion Paper 281, September 2006

Armstrong, M. and Vickers, J. (2008) "Competitive Nonlinear Pricing and Bundling" forthcoming, Review of Economic Studies

Bonatti, A. (2008) "Brand-Specific Tastes for Quality" Working Paper, November

Bradley, I. and Price, C. (1988) "Economic Regulation of Private Monopolies through

Price Constraints" Journal of Industrial Economics vol. 37 p. 99-106

Busse, M.R. (2000) "Multimarket Contact and Price Coordination in the Cellular Telephone Industry" Journal of Economics and Management Strategy vol.9 p.287320

Busse, M.R. and Rysman, M. (2005) "Competition and Price Discrimination in Yellow Pages Advertising" RAND Journal of Economics vol.36 p.378-390

Champsaur, P. and Rochet, J.-C. (1989) "Multiproduct Duopolists" Econometrica vol.57 p.533-557

Champsaur, P. and Rochet, J.-C. (1990) "Price Competition and Multiproduct Firms" in "Essays in Honor of Edmond Malinvaud" vol.1 p. 162-187, MIT Press

Cohen, A. (2008) "Package Size and Price Discrimination in the Paper Towel Market" International Journal of Industrial Organization vol.26 p. 502-516

Cornwall, N. (2008), Gas and Electricity costs to consumers, published by the National Right to Fuel Campaign

Department of Energy and Climate Change (2008) Quarterly Energy Prices

Giulietti, M and Waddams Price, C. (2005) "Incentive Regulation and Efficient Pricing Structures" Annals of Public and Co-operative Economics, 76, 1, 1121-138 
Harker, M. and Waddams Price, C. (2007) "Introducing Competition and Deregulating the British Domestic Energy Markets: A Legal and Economic Discussion" Journal of Business Law p. 244-268

Leslie, P. (2004) "Price Discrimination in Broadway Theater" RAND Journal of Economics vol.35 p.520-541

Maskin, E. and Riley, J. (1984) "Monopoly with Incomplete Information" RAND Journal of Economics vol.15 p.171-196

McManus, B. (2007) "Nonlinear Pricing in an Oligopoly Market: The Case of Speciality Coffee" RAND Journal of Economics vol.38 p.512-532

Miravete, E.J. (2007) "The Limited Gains from Complex Tariffs" Working Paper, September 2007

Miravete, E.J. and Röller, L-H (2004) "Estimating Markups Under Nonlinear Pricing" Journal of the European Economic Association vol.2 p.526-535

Mussa, M. and Rosen, S. (1978) "Monopoly and Product Quality" Journal of Economic Theory vol.18 p.301-317

Ofgem (2003) Domestic Gas and Electricity Supply Competition Recent Developments, June

Ofgem (2008) Energy Supply Probe - Initial Findings Report, October

Rochet, J-C. and Stole, L. A. (2002) "Nonlinear Pricing with Random Participation" Review of Economic Studies vol.69 p.277-311

Seim, K. and Viard, V.B. (2008) "The Effect of Market Structure on Cellular Technology Adoption and Pricing" Working Paper, January 2008

Stole, L. A. (2007) "Price Discrimination and Competition" in "Handbook of Industrial Organization Vol.3", M. Armstrong and R. Porter (Eds.) Amsterdam: Elsevier p. 2221-99

Wilson, C.M. and Waddams Price, C. (2008) "Do Consumers Switch to the Best Supplier?" ESRC Centre for Competition Policy Working Paper

Wooldridge, J. M. (2002), Econometric Analysis of Cross Section and Panel Data. Cambridge, MA: MIT Press.

Yang, H. and Ye, L. (2008) "Nonlinear Pricing, Market Coverage, and Competition" Theoretical Economics vol.3 p.123-153

Yin, X. (2004) "Two-Part Tariff Competition in Duopoly" International Journal of Industrial Organization vol.22 p.799-820 